\title{
CURRÍCULOS DA EDUCAÇÃO BÁSICA BRASILEIRA: CONVERGÊNCIAS COM O DISCURSO EDUCACIONAL GLOBAL EM CONTEXTOS DE INTERNACIONALIZAÇÃO
}

\author{
CURRÍCULOS DE LA EDUCACIÓN BÁSICA BRASILEÑA: CONVERGENCIAS CON \\ EL DISCURSO EDUCACIONAL GLOBAL EN CONTEXTOS DE \\ INTERNACIONALIZACIÓN
}
BRAZILIAN BASIC EDUCATION CURRICULA: CONVERGENCES WITH THE GLOBAL EDUCATIONAL DISCOURSE IN CONTEXTS OF INTERNATIONALIZATION

Juares da Silva THIESEN ${ }^{1}$

RESUMO: No texto, analiso o progressivo alinhamento da Educação Básica brasileira aos movimentos pela internacionalização da educação, com especial atenção às estratégias que Estados, Organismos Transnacionais e iniciativa privada vêm mobilizando com a expectativa de ajustarem configurações curriculares de escolas a essa perspectiva que se hegemoniza em escala global. A discussão é feita com base nos conceitos de discurso educacional e acadêmico global de Jason Beech, além de outros, associados com análise das políticas educacionais e curriculares. Aponto que no Brasil as estratégias afetam mais fortemente dinâmicas que envolvem gestão escolar, desenhos curriculares, conteúdos de conhecimento e formação de professores.

PALAVRAS-CHAVE: Currículo. Internacionalização. Educação básica. Discursos globais.

RESUMEN: En el texto, analizo la progresiva aproximación de la Educación Básica brasileña con los movimientos por la internacionalización de la educación, con especial atención a las estrategias que Estados, organismos transnacionales e iniciativa privada vienen movilizando con la expectativa de ajustar configuraciones curriculares de las escuelas a esa perspectiva hegemonizada en escala mundial. La discusión se hace con base en los conceptos de discurso educativo y académico global (Beech, 2012) además de otros asociados con el análisis de las políticas educativas y curriculares. Como resultado, apunto que en Brasil las estrategias afectan más fuertemente dinámicas que involucran gestión escolar, diseños curriculares, contenidos de conocimiento y formación de profesores.

PALABRAS CLAVE: Currículo. Internacionalización. Educación básica. Discursos globales.

ABSTRACT: This paper analyzes the progressive alignment of Brazilian Basic Education to movements for the internationalization of education. Special attention is given to strategies of states, transnational organizations and the private sector to adjust school curricula to this

${ }^{1}$ Universidade Federal de Santa Catarina (UFSC), Florianópolis - SC - Brasil. Professor do Departamento de Estudos Especializados em Educação. ORCID: <https://orcid.org/0000-0001-9299-4441>. E-mail: juares.thiesen@ufsc.br

RIAEE - Revista Ibero-Americana de Estudos em Educação, Araraquara, v. 14, n. 2, p. 420-436, abr./jun., 2019. E-ISSN: $1982-5587$. 
perspective that has become hegemonic worldwide. The discussion is based on the concepts of global educational and academic discourse (Beech, 2012) and on others associated to the analysis of educational and curricular policies. I show that in Brazil, the strategies more strongly affect dynamics that involve school administration, curriculum design, contents of knowledge and teacher education.

KEYWORDS: Curriculum. Internationalization. Basic education. Global discourses.

\section{Introdução}

O trabalho em pauta resulta de pesquisa que desenvolvo em estágio pós-doutoral no Instituto de Educação da Universidade do Minho, Portugal, e que tem por objetivo analisar implicações dos movimentos de internacionalização curricular no/do Ensino Superior sobre as atuais políticas e reconfigurações curriculares da Educação Básica, particularmente nos cenários de Brasil e Portugal.

Como recorte da pesquisa mais ampla, analiso no texto o envolvimento da Educação Básica brasileira, especialmente sua configuração curricular, aos movimentos pela internacionalização. Nesse âmbito, exploro elementos que indicam como e com que intensidade as estratégias mobilizadas pelo Estado brasileiro e pela iniciativa privada implicam sobre dinâmicas da organização escolar em termos curriculares, especialmente na gestão do currículo, em aspectos que envolvem mecanismos de avaliação, arquiteturas curriculares, conteúdos de conhecimentos e formação de professores.

Em trabalhos anteriores no âmbito desta mesma investigação, tratei, respectivamente: i) da identificação e discussão de conceitos e de contextos sociopolíticos que envolvem a problemática da internacionalização da educação; ii) de possíveis alinhamentos da política curricular oficial brasileira a esse projeto que se hegemoniza em escala mundial e, ainda, das estratégias mobilizadas pelo Estado e pela iniciativa privada para alinhar o sistema educacional brasileiro aos requerimentos e expectativas da internacionalização.

O pressuposto a partir do qual ancoro meus argumentos é que existe atualmente no Brasil um conjunto de ações oficiais e não estatais mobilizadas com intenção de aproximar os currículos da Educação Básica aos requerimentos, demandas e expectativas da internacionalização - um movimento evidente e expressivo na Educação Superior e que avança para este nível de ensino. A afirmação sustenta-se em outros resultados evidenciados no âmbito desta mesma pesquisa e em trabalhos de pesquisadores, a exemplo do que produziram Amorim (2012), Libâneo (2014), Sevilha (2014), Aguiar (2009), Silva Jr, Lucena e Ferreira (2011) e Souza (2016). 
Para compreender a problemática da internacionalização no contexto das políticas educacionais em escala transnacional, amparo-me em trabalhos de Ball (2014), Dale (2004, 2010), Beech (2012), Cowen (2012), Freitas (2012), além de outros. Recorro especialmente aos seus textos para defender que as estratégias que o Brasil vem mobilizando no campo da educação na perspectiva da internacionalização, inclusive na Educação Básica, formam parte de um orquestramento geoeconômico e político em escala global, que em termos teóricodiscursivos, recebe diferentes denominações ou conceitos dependendo do enfoque e do recorte que fazem seus autores.

Assumo também, com base em trabalhos anteriores, que na Educação Básica brasileira as estratégias orientadas para a perspectiva da internacionalização estão sendo discretamente inseridas nas políticas educacionais, seja por meio das prescrições curriculares oficiais, de projetos e programas, por mecanismos de avaliação, pelo financiamento ou ainda por outras formas de regulação e controle. E que estas estratégias alteram, em alguma medida, as dinâmicas da organização escolar.

O texto está organizado de modo que na primeira seção retomo e amplio discussões que venho fazendo no sentido de situar os contextos nos quais os movimentos pela internacionalização da educação e do currículo se fortalecem, com especial atenção aos conceitos de discurso educacional global e discurso acadêmico global (Beech, 2012) e na segunda seção analiso como as estratégias que estão sendo efetivadas no âmbito da Educação Básica afetam as dinâmicas curriculares. Trata-se, portanto, de um estudo empírico-teórico que se serve de resultados parciais já alcançados no contexto desta mesma investigação e da exploração de outros textos, inclusive de documentos oficiais da política educacional brasileira.

\section{Contextos e discursos nos quais currículos da Educação Básica brasileira se encontram e se identificam com movimentos pela internacionalização}

A expressão “novas crianças passeando pelo parque global” que Beech (2012, p. 414), utiliza para abrir, no seu texto, a discussão sobre os conceitos de transferência, movimento e influência nas políticas educacionais contemporâneas, sugere a dimensão do que representa para a educação, na atualidade, a existência do que ele mesmo denomina um discurso educacional global e um discurso acadêmico global. A expressão é, pois, alusiva às metanarrativas destes discursos, os quais colocam os sentidos da formação humana escolarizada, desde as fases mais elementares às altamente especializadas, num mesmo circuito em termos de racionalidade conceitual e alinhamento teleológico. Um parque gigante, porém, 
único para todas as crianças. No entendimento de Popkewitz (2012) a expressão, todas as crianças, incorporou uma obrigação de comparar a unidade ao todo em relação ao qual a diferença se estabelece. A reiteração contínua subsequente em declarações ligadas às políticas sobre reformas escolares, no sentido de que "todas as crianças aprenderão" e de que os programas "servem a todos os alunos", criam um espaço de participação mística em um bem comum que, na realidade, diferencia e divide.

Num mundo culturalmente diverso, politicamente controverso e economicamente injusto, cresce a força de um espectro que ganha a forma de uma monstruosa rede políticoeconômica e que, rapidamente, vai abocanhando parte significativa daquilo que historicamente vinha nutrindo o horizonte utópico de sociedades que sonharam e, de algum modo, ainda sonham com um mundo constituído por práticas humanas mais livres, criativas e emancipadoras. Vivemos tempos de orquestramentos executados em escalas transnacionais em que se conjugam melodiosamente os tons de uma governação global, governação essa explicitamente chancelada pelos estados-quase-mercados, que se arroga a formular e propor ao mundo uma agenda estruturada para a educação (DALE, 2010) e que é apresentada como pauta única para o universo global das sociedades, indicando ser este o melhor (se não o único) caminho para a educação e o desenvolvimento no contemporâneo.

Com finalidades mais amplas em termos de governança transnacional, essas redes políticas (BALL, 2014) colocam a educação como um imperativo social e econômico e lançam mão de variadas estratégias para colocá-la na pauta das grandes questões atuais à razão e ao crivo de seus interesses. Neste âmbito, organizam as 'bem formuladas' recomendações internacionais suportadas desde a construção de um discurso global para a educação que rapidamente se institucionaliza e se hegemoniza. Pauta que inclui, dentre várias outras demandas da política educacional global, a estratégia da internacionalização das instituições educativas e de seus currículos - movimento este que se sustenta na competição deliberada, sem constrangimentos, pelas leis de mercado, e negocia, como qualquer outro serviço ou produto, o conhecimento acadêmico, a produção científica, os talentos e inclusive a formação escolar básica em alguns contextos. Costa (2011) assinala que os governos usam as ações de governança intergovernamental como instrumentos para alargarem a sua área de competência e retirar dos atores internos o controle da tomada de decisões.

Para Beech (2012), o discurso global é construído por meio da estruturação articulada de uma teoria geral da circulação do discurso no campo da educação global que envolve vários atores e agentes em posições distintas, dentre eles, o espaço acadêmico global, as agências internacionais, o Estado, os espaços acadêmicos locais e as instituições educacionais. 
Chancelados que são pela força das redes políticas globais que se instituem, atuam com racionalidades similares ou convergentes como bem nomeiam Altbach (2000) e Costa (2011).

Nesta mesma linha argumenta Cowen (2012), ao tratar da educação comparada, quando afirma que esse é o esforço atual (da globalização) que tem por objetivo redefinir os conceitos interpretativos utilizados para considerar novas relações internacionais de poder e a reestruturação do sistema mundial. Para cada geração de trabalho acadêmico, essas preocupações incluem - em diversos níveis de sofisticação e de acuidade teórica - os espaços sociais e as relações espaço-tempo por meio das quais fluem ideias e práticas, internacionalmente e transnacionalmente.

Notadamente formam parte dessa vibrante orquestra de governação global os organismos multilaterais; gestores políticos ligados à administração dos estados nacionais, especialmente os considerados economicamente centrais; equipes gestoras de instituições públicas consideradas estratégicas; representantes de comunidades epistêmicas, especialmente de conceituadas associações científicas; empresários, especialmente os ligados com serviços e produção de tecnologias; consultores internacionalmente reconhecidos, além de outros. Como bem ilustra Beech (2012), consultores carismáticos viajam pelo mundo recomendando suas soluções e promovendo mudanças educacionais em nível de escola, distrito e estado.

No caso específico da internacionalização da educação, o espaço acadêmico global assume papel relevante, tendo em vista ser ele um núcleo de informação e de conhecimento institucionalizado e compor, em geral, o cérebro de agências ou organismos multilaterais que controlam os discursos globais neste campo. Beech (2012) entende que o espaço acadêmico global é o local de criação seletiva e alteração de ideias e onde são desenvolvidos os discursos acadêmicos especializados. É por onde passam os fluxos de ideias que atravessam as redes, sejam elas sociais, acadêmicas ou políticas. Os documentos de orientação ou recomendação educacional de instituições como a OCDE, a UNESCO e o Banco Mundial, são bons exemplos disso.

Outro aspecto importante apontado pelo pesquisador Argentino, que segundo ele, vem marcando o discurso global, materializado especialmente nos textos dos documentos das principais organizações e agências transnacionais, é o de supersimplicação de seus conteúdos, estejam eles relacionados com teorias, conceitos ou estratégias. Ball (1998) argumenta que uma das razões da simplificação nos textos das políticas tem a ver com a atratividade e aderência que propostas objetivas, claras e pragmáticas alcançam junto à estados nacionais e sistemas educacionais. 
Nessa direção, Estados mais bem colocados nos rankings das estratégias e de resultados em termos de internacionalização da educação formam coro com as agências e demais redes transnacionais hegemonizando um discurso educacional e acadêmico global, no qual as complexidades teóricas, contextuais e políticas são suprimidas e seus textos convertidos em verdadeiros manuais sobre como aderir ao movimento e o que fazer em termos operacionais para seguir o exemplo de quem já sabe fazer com eficiência.

Assim, Estados periféricos, que ainda precisam aprender como fazer, se satisfazem em implantar modelos já testados. Basta que eles invistam na mobilidade de seus estudantes, aumentando as matrículas nas instituições educativas dos países centrais, que exportem seus cérebros para fortalecer ainda mais as desigualdades cognitivas regionais, que acolham em seus territórios a expansão, via franquia, dos campi de renomadas instituições de países que sabem e fazem internacionalização exemplarmente, que recebam bem e acatem as orientações dos consultores internacionais nos seus planejamentos institucionais de internacionalização, que colaborem participando, ainda que passivamente, das redes de pesquisa, de acordos de cooperação, de programas de formação e qualificação em contextos internacionais, etc.

Essa racionalidade que se impõe como solução contemporânea para a educação e alcança, com força, os sistemas de Educação Superior na ampla maioria dos Estados Nacionais, vai ocupando também os espaços dos sistemas que administram a Educação Básica, ainda que num ritmo menos acelerado e com menor agressividade. Essa diferença de velocidade e intensidade ocorre fundamentalmente porque a Educação Básica não possui o mesmo peso e valor econômico que a Educação Superior na balança de comercialização do ensino em escala regional e global. Observa-se, entretanto, que nessa etapa de escolarização é o Ensino Médio que tem despertado maior interesse, especialmente pelas possibilidades que oferece de exploração da mobilidade estudantil em escala internacional.

De toda forma, os primeiros passos na direção do envolvimento da Educação Básica com os movimentos de internacionalização se efetivam por meio de estratégias que incluem reformulações nos textos das políticas curriculares, reconfigurações ou adequações dos currículos escolares, implantação de programas oficiais de incentivo a formação inicial e continuada em contextos de cooperação internacional, programas específicos de incentivo a mobilidade de professores e estudantes, criação de escolas internacionais, fortalecimento de intercâmbios do tipo high school, além de outras.

\section{A gestão dos currículos escolares na rota da internacionalização}


Estudos que analisam o fenômeno da internacionalização da educação apontam ser consensual o entendimento que o currículo constitui território central no conjunto das estratégias adotadas por instituições educacionais visando ajustarem-se aos requerimentos e demandas da internacionalização. Não é por acaso que pesquisadores reconhecidos como Leask (2009, 2015) e Knight $(2004,2008)$ preferem analisar a internacionalização a partir ou nos espaços do currículo. A expressão IoC (Internationalisation of the Curriculum), já utilizada largamente em trabalhos que discutem esta temática, dá pistas da relevância deste recorte no conjunto da produção teórica sobre internacionalização da educação. Arrisco-me a dizer que não há como operar qualquer estratégia de internacionalização no campo educacional sem que haja mobilização de ações no território curricular.

No Brasil, as estratégias mobilizadas pelos sistemas de ensino no território do currículo escolar com vistas aos alinhamentos da formação escolar aos requerimentos e demandas da internacionalização estão relacionadas com ações que envolvem predominantemente a gestão curricular em aspectos que incluem avaliação de rendimento escolar, seleção e proposição de conteúdos de conhecimentos, arquiteturas curriculares e formação de professores. Detalharei brevemente cada um deles, tendo em conta que estes aspectos constituem parte de uma mesma unidade/totalidade nos movimentos da experiência escolar.

a) Avaliação de rendimento escolar: pressões focadas em performances;

São vários os trabalhos de pesquisa ${ }^{2}$ que afirmam haver, sobretudo a partir dos anos 1980, movimentos institucionalizados em escala transnacional, visando transferência ou incorporação de modelos de governança gerencial do setor privado para os setores públicos em geral e deles para a educação em particular. A força desse discurso global, que rapidamente invadiu os órgãos de gestão dos sistemas públicos de ensino, não poupou os espaços da gestão escolar que cada vez mais se veem colocados no centro de uma forte contradição, quando tentam articular autonomia escolar e gestão democrática com performance e eficiência nos resultados.

Grancho (2008), ao tratar da relação entre autonomia escolar no quadro das influências internacionais em Portugal, avalia que a prestação de contas (accountability) surge como contraponto necessário à substituição da gestão direta e centralizada pela regulação, devendo as escolas assumir a auto-avaliação e a avaliação externa como componente necessário ao seu

${ }^{2}$ Exemplos de trabalhos que tratam da problemática: Gewirtz e Ball (2011); Medeiros e Rodrigues (2014); Pieranti, Rodrigues e Peci (2008). 
desenvolvimento como instituições, como um sistema de pilotagem mais capaz de gerir a sua autonomia num quadro de uma administração descentralizada. De fato, a descentralização da gestão escolar, atrelada à prestação de contas por mecanismos da avaliação externa, tornou-se uma das principais estratégias de regulação e controle do Estado-quase-mercado (AFONSO, 1998) no horizonte das perspectivas de fundo neoliberal.

No Brasil, o fim dos anos 1980 marca um tempo de abertura política e com ele a expectativa de maior participação coletiva na gestão das instituições públicas. Na educação, emergem com força os ideários de autonomia escolar e gestão democrática e fortalecimento dos projetos políticos pedagógicos - PPP - expectativas convertidas em direito nas normas educacionais promulgadas nos anos que se seguiram, notadamente na Constituição de 1988 e na Lei de Diretrizes e Bases de 1996. Todavia, não tardaram o retorno às pressões externas denunciando os baixos resultados em termos de rendimento escolar e, ao mesmo tempo, oferecendo soluções mais eficientes, eficazes e inovadoras. São exemplos disso a crescente oferta de assessorias para a formulação de sistemas de avaliação externa tanto no Ensino Superior quanto na Educação Básica; de pacotes de gerenciamento escolar com foco em resultados por empresas privadas, algumas delas multinacionais; a formulação e implantação de programas de monitoramento de rendimentos escolares como é o Programa de Desenvolvimento da Educação - PDE incluindo todos os seus subprojetos; e a formação de gestores escolares em serviço - sustentados, por vezes, em concepções gerencialistas focados especialmente no alcance de resultados e méritos escolares.

As racionalidades e discursos identificados com internacionalização, nesse âmbito, aparecem manifestados em pelo menos três frentes ou estratégias: i) aquelas decorrentes de demandas diretamente apresentadas pelos organismos multilaterais os quais passam a controlar, ainda que indiretamente, a distribuição do financiamento, da avaliação dos resultados escolares e da (re)formulação de diretrizes curriculares, ii) as relacionadas com os programas oficiais nos quais o Estado vincula expectativas de resultados em função de padrões e exigências internacionais - a exemplo do que faz em programas como o PAR - Programa de Ações Articuladas, e neste âmbito o PDE Escola e o IDEB, e iii) as relacionadas com oferta de soluções educativas para a gestão de resultados escolares geralmente apresentadas por empresas privadas que colocam ranqueamentos e padrões internacionais como referência em seus discursos comerciais.

Independentemente das estratégias propostas e/ou adotadas pelos sistemas locais de ensino e consequentemente pelas escolas em cada uma das frentes, o que está em jogo (mais uma vez) é a autonomia escolar - com o risco de perda de uma difícil luta histórica que a duras 
penas colocou o currículo como um território a serviço da formação humana, identificado, de algum modo, com as expectativas sociais e culturais mais imediatas dos sujeitos, sem prescindir, obviamente, dos conhecimentos científicos a que têm direito.

b) Seleção e proposição de conteúdos de conhecimentos;

Tão consensual quanto a ideia que o currículo é território estruturante nas estratégias de internacionalização da educação, está a premissa que o conhecimento constitui ferramenta nuclear para sua consecução. E esta tese não é nova. Desde os tempos de Franklim Bobbitt (1876-1956), W. W. Charters (1875-1952) e David Snedden (1868-1951), no início do século $\mathrm{XX}$, que os liberais apostam na reformulação das arquiteturas curriculares e na seleção/proposição de conteúdos de conhecimento escolares, como alternativas para fazer avançar, eficientemente, o progresso econômico das nações e a expansão de liderança nos espaços internacionais. Se no caso dos EUA, na época, a expectativa maior era colocar o país na vanguarda mundial, hoje se alteram as finalidades, entretanto, permanecem, em vários aspectos, as racionalidades que sustentaram aquela teoria curricular de inspiração em pressupostos da administração científica antes assumida por Frederick W. Taylor (Kliebard, 2011) e que agora é, em alguma proporção, retomada nas formulações econômicas das redes de governança neoliberais. Como bem afirma Dale (2008, p. 18),

O isomorfismo curricular em nível mundial que observamos não é o produto da globalização, como se considera atualmente, mas possui uma história muito mais longa, associada à propagação dos valores e pressupostos da modernidade, tais como a racionalidade científica, o individualismo e o progresso.

Nesse sentido, o conhecimento (inclusive o escolar) jamais escapou aos olhos dos dirigentes econômicos e políticos, mas atualmente assume valor maior, afinal vivemos a era do conhecimento e da informação (CASTELS, 1997) e o mundo move-se por dinâmicas que o envolve nas mais diferentes formas de exploração. Para além de um bem coletivo e um direito público, o conhecimento passa a ser uma importante commodity no conjunto dos demais produtos que circulam no mercado, sobretudo em escalas regional e global.

Vale marcar aqui o exemplo da Educação Superior. Os indicadores relacionados com o mercado neste nível de ensino em contextos de internacionalização, cujo principal produto negociado é o conhecimento, são surpreendentes. Sobre este aspecto, Knight (2014) elabora um interessante panorama situando o crescimento do movimento no que chama de gerações da 
Internationalization of Higher Education e destaca a ampliação dos números relacionados criação e implantação de Centros Educacionais Internacionais (International Hubs Education), envolvendo especialmente mobilidade acadêmica, abertura de unidades universitárias em outros países (International branch campus-IBC), modernização tecnológica de universidades, recrutamento de docentes e pesquisadores de alto nível, ampliação de investimentos em P\&D e inovação, criação e implantação de sistemas de gestão do conhecimento, desenvolvimento de talentos, além de outros. Tudo isso, movido pela energia do conhecimento mercadoria.

No nível da Educação Básica, o valor do conhecimento que circula nos territórios curriculares da formação escolar também tem sido, mais que nunca, objeto de intensa disputa. Em termos gerais, poderíamos dizer que esta tensão se coloca principalmente em relação às concepções, perspectivas e finalidades de quem o produz e o propõe curricularmente, na medida que cada qual (pessoas ou grupos) busca, ao afirmar determinado conhecimento, espaços de reconhecimento e porque não de hegemonia.

Nesse cenário, tornam-se evidentes as concepções, perspectivas e finalidades que sustentam o hegemônico discurso educacional global e também o discurso acadêmico global no que se refere aos valores e funções do conhecimento escolar/acadêmico, tanto na educação superior quanto na básica, em contextos de internacionalização da educação. Este artefato cultural/humano a partir da qual é constituída a formação escolar tem sido apresentado pelos representantes destas redes políticas de governança transnacional como matéria prima ou ativo intangível (DAVENPORT, 1999) fundamental para o aperfeiçoamento da cidadania global (UNESCO, 2015), horizonte que demanda currículos que desenvolvam nos estudantes competências interculturais e globais, formação para empregos qualificados, atitudes e valores democráticos. $\mathrm{Na}$ área acadêmica da Gestão do Conhecimento, por exemplo, é consensual a tese que o conhecimento é o bem mais valioso da nova economia. Conhecimento esse produzido pelo trabalhador, agora renomeado pelo mercado de ativo intangível. (DAVENPORT, 1999; STEWART, 1998).

O contexto é, portanto, favorável para que sistemas de ensino e escolas ajustem seus currículos de modo que os conhecimentos sejam selecionados e ministrados em conformidade com perspectivas de transnacionalização e internacionalização. Não é por acaso que o chamado currículo por competências, oficialmente chancelado pelo Estado brasileiro ${ }^{3}$, esteja invadindo os territórios curriculares das escolas. Associado a esse conceito se fortalecem outras proposições, a exemplo da redução do tempo para conteúdos das Ciências Humanas

${ }^{3}$ Refiro-me ao texto aprovado recentemente pelo Conselho Nacional de Educação que define uma Base Nacional Comum Curricular - BNCC, para as escolas de Educação Básica do País. 
(notadamente a sociologia e a filosofia), das artes e outros relacionados com cultura local e amplia-se a presença de conteúdos das chamadas ciências duras, línguas estrangeiras e tecnologia, esta última vinculada à profissionalização. Maués, Wondje e Gauthier (2004) consideram que o modelo de competências aparece na educação brasileira como uma senha que vai permitir a entrada no mundo contemporâneo e o alinhamento com a tendência internacional no que se refere à educação.

c) Arquiteturas curriculares;

No que se refere aos redesenhos curriculares, os discursos são bem situados e em convergência com as demandas e expectativas da internacionalização. Assim, é cada vez mais comum chegar às escolas brasileiras, discussões subsidiadas por textos que recomendam flexibilização curricular, ampliação de jornada escolar, avaliação e gestão de resultados, abertura de maior espaço para áreas ligadas às tecnologias, línguas estrangeiras e disciplinas que são objetos de avaliação pelos organismos externos à escola.

Exemplo contundente desta racionalidade é o texto da atual reforma do Ensino Médio brasileiro que propõe uma nova arquitetura curricular para esta etapa de ensino, formato que inclui flexibilização dos itinerários formativos, ampliação de carga horária do curso com consequente aumento do tempo escolar diário, redução do número de disciplinas (principalmente as de formação política e cultural) e profissionalização de jovens pela via da formação técnica. Uma proposta notadamente orientada por consultores internacionais com inspiração em experiências de países considerados desenvolvidos e feita por medida provisória, portanto, sem ouvir os profissionais da educação e a sociedade brasileira.

Às estratégias oficiais, conjugam-se outras iniciativas provenientes do setor privado, cada vez mais presente nos espaços da educação pública com ofertas de soluções curriculares que incluem novas arquiteturas, em geral mais modernas, condizentes com os padrões de qualidade internacional, adequadas ao tempo tecnológico em que vivemos, inovadoras do ponto de vista de seus recursos e eficientes no alcance de resultados. São proposições suportadas por discursos sedutores que vendem os mesmos ideários marcados globalmente nos textos da agenda estruturada para a educação (DALE, 2001) pelas atuais redes políticas transnacionais (BALL, 2014).

Vale lembrar que a opção pela alteração de um determinado desenho ou arquitetura curricular não implica somente numa questão de forma. Ao fazê-lo, alteram-se todos os processos que envolvem a formação, incluindo seus pressupostos, conteúdos, procedimentos e 
finalidades. Afinal, a escolha do desenho ou modelo do currículo não é uma entidade objetiva e exclusivamente racional, mas sim uma construção social, política, acadêmica e profissional (GRANT, 2010).

d) Formação de professores;

No conjunto dos trabalhos que discutem internacionalização envolvendo Educação Básica, alguns são dedicados à investigação da problemática da formação e atuação de professores, a exemplo do que produziram Landwehr (2012), Beelen (2006), Shaklee e Baily (2012). Em geral, são textos que tratam de aspectos que envolvem qualificação de professores (e de estudantes futuros professores) para atuação em contextos de internacionalização da educação e do currículo, contemplando especialmente a necessidade de aprendizagem e ensino de competências linguísticas e interculturais em níveis de demanda internacional e global.

No contexto internacional, tanto o discurso educacional global quanto o acadêmico global sobre qualificação e atuação de professores marcam contundentemente a necessidade do desenvolvimento de competências globais para o exercício da atividade. O prefácio do documento intitulado Teacher preparation for the global age the imperative for change (2008 p. 3) da Longview Foundation for World Affairs and International Understanding é ilustrativo neste aspecto quando nele afirma-se que: "The critical role of teachers in internationalizing $P$ 12 education has never been clearer, yet today's educators rarely begin their careers with the deep knowledge and robust skills necessary to bring the world into their classrooms".

No Brasil, todavia, não há pesquisas dedicadas a investigar este problema, o que nos leva a supor que o tema não constitui, ainda, um problema ou necessidade que mereça tratamento acadêmico. Os poucos trabalhos dedicados a formação e atuação dos professores em contextos de internacionalização analisam resultados e repercussões de programas apoiados pela Coordenação de Aperfeiçoamento de Pessoal do Ensino Superior - CAPES, notadamente o de Licenciaturas Internacionais (PLI) e os decorrentes de convênios deste mesmo órgão oficial com instituições estrangeiras. Nesse âmbito, destaca-se o texto de Luna e Alexandre (2015), que discute referenciais de competência comunicativa intercultural para a educação básica em contextos de internacionalização do currículo, trabalho no qual os autores apontam sugestões no âmbito da atuação de professores.

O quadro nos sugere pensar que no Brasil as adequações dos currículos escolares visando alinhamentos com a internacionalização ocorrem mais no âmbito da sua reorganização interna em termos de gestão, arquitetura e seleção/proposição de conteúdos de conhecimentos 
do que de qualificação dos professores. Aliás, esta tem sido a marca histórica da política curricular brasileira, qual seja, alterar a configuração dos currículos sem a devida preparação dos professores que os desenvolvem.

\section{Palavras finais}

A opção que fiz no trabalho, de apontar algumas estratégias de aproximação e alinhamento da gestão dos currículos escolares na Educação Básica às racionalidades que orientam os movimentos pela internacionalização da educação, atribuindo maior ênfase aos aspectos de natureza político-econômica do que propriamente aos pedagógicos, deve-se, conforme destaquei no texto, pelas evidências de força que os discursos dessas redes políticas de escala transnacional exercem sobre a formulação das políticas curriculares nos sistemas oficiais de ensino.

A escolha por esta abordagem, de modo algum, deve sugerir que interpreto os movimentos da educação em geral e das políticas e práticas curriculares em particular, sem levar em conta que são processos altamente dinâmicos e marcadamente complexos nos quais se revelam interesses de distintas ordens, sejam eles derivados de pensamentos e práticas individuais, coletivas ou institucionais. Portanto, reafirmo meu entendimento, considerando que são relevantes as influências e as implicações dos discursos hegemonizados em escala global sobre as dinâmicas curriculares escolares, todavia, operam nestes processos, variadas formas de tradução, (re)elaboração, negociação e resistência.

Dois outros aspectos têm se mostrado caros ao debate político da internacionalização da educação e do currículo e, por isso, precisam ser marcados aqui, ainda que brevemente. $\mathrm{O}$ primeiro deles é afirmar meu entendimento que práticas educacionais e curriculares mobilizadas em perspectivas de internacionalização, quando pensadas e desenvolvidas sobre bases teóricas consistentes e sobre finalidades eminentemente acadêmicas (portanto, não comerciais), podem contribuir significativamente para elevar a qualidade da educação pública em geral e dos percursos curriculares de formação em particular. Portanto, o que está colocado como questão não é a importância da internacionalização da educação e dos currículos como ampliação universal do direito de todos os cidadãos ao conhecimento e à formação escolar de qualidade, mas sim, à imposição de outras finalidades - nem sempre explicitadas nos discursos das referidas redes políticas.

E, finalmente, marcar que as reconfigurações curriculares, sejam elas dinamizadas por motivações derivadas da internacionalização ou de qualquer outra perspectiva, são 
fundamentalmente importantes, contanto que caminhem na direção da ampliação dos direitos de estudantes (e demais profissionais da educação), à cultura e aos conhecimentos produzidos historicamente pelos coletivos humanos e, sobretudo que promovam a eles maior acesso aos bens culturais, da escala local à global.

\section{REFERÊNCIAS}

AFONSO, Almerindo Janela. Estado, mercado, comunidade e avaliação. Revista Crítica de Ciências Sociais. Coimbra: n. 51, p. 109-135, jun. 1998.

AGUIAR, Andrea Moura de Souza. Estratégias educativas de internacionalização: uma revisão da literatura sociológica. São Paulo, Educação e Pesquisa, v. 35, n. 1, p. 067-079, jan./abr. 2009.

ALEXANDRE, Aline Facchini e LUNA, José Marcelo Freitas. Do referencial de competência comunicativa intercultural para o seu desenvolvimento na Educação Básica. Passo Fundo, Revista do Programa de Pós-Graduação em Letras da Universidade de Passo Fundo, v. 11, n. 2, p. 261-276, jul./dez. 2015.

ALTBACH, Philip. Patterns in Higher Education Development: Toward the Year. The Review of Higher Education, v. 14, n. 3, p. 293-315, 2000.

AMORIM, Marina Alves. Educação dos Brasileiros e o Estrangeiro: breve histórico da internacionalização dos estudos no Brasil. Brasiliana, Journal for Brazilian Studies, v. 1, n. 1, set.. 2012.

ARROYO, Miguel Gonzalez. Currículo, território em disputa. Petrópolis, Rio de Janeiro: Vozes. 2011.

BALL, Stephen J. Big policies/small world: An introduction to international perspectives in education policy. Comparative Education, v. 34, n. 2, p. 119-130, 1998.

BALL, Stephen J. Educação Global S.A. novas redes de políticas e o imaginário neoliberal. Tradução de Janete Bridon. Ponta Grossa, Brasil: UEPG, 2014.

BEECH, Jason. Quem está passeando pelo jardim Global? Agências educacionais e transferência educacional. In: COWEN, Robert; KAZAMIAS, Andreas M. e ULTERHALTER, Elaine (orgs). Educação comparada: panorama internacional e perspectivas. Brasília, UNESCO, CAPES, 2012.

BEELEN, Jos. Internationalising the School Curriculum: International Competences for Teachers. 31st Annual ATEE conference. Portoroz, 21 October t/m 25 October, 2006. Anais. Disponível em: http://archive.atee1.org/conferences_and_seminars/9/31st_annual_atee _conference_2006_portoroz.html\#algemeen. Acesso em: 10 fev. 2017.

BRASIL. Ministério da Educação. Base Nacional Comum Curricular - BNCC. Disponível em: http://basenacionalcomum.mec.gov.br. Acesso em: 01 out. 2017. 
CASTELLS, Manuel. The information age: economy, society and culture. Oxford: Blackwell Publishers, 1997.

COSTA, Estela Mafalda Inês Elias Fernandes da. O Programme for International Student Assessment (PISA) como instrumento de regulação das políticas educativas. 2011. Tese Educação (Administração e Política Educacional), Universidade de Lisboa, IEUL, 2011.

COWEN, Robert. Introdução: o nacional, o internacional e o global. In: COWEN, Robert; KAZAMIAS, Andreas M. e ULTERHALTER, Elaine (org). Educação comparada: panorama internacional e perspectivas. Brasília, UNESCO, CAPES, 2012.

DALE, Roger. Globalização e educação: demonstrando a existência de uma "cultura educacional mundial comum" ou localizando uma agenda globalmente estruturada para a educação? Campinas, Educação e Sociedade, v. 25, n. 87, p. 423-460, mai./ago. 2004.

DALE, Roger. A globalização e o desenho do terreno curricular. Espaço do Currículo, v. 1, n. 1, p. 12-33, mar./set. 2008.

DALE, Roger. A sociologia da educação e o estado após a globalização. Campinas, Educação e Sociedade, v. 31, n. 113, p. 1099-1120, out./dez. 2010.

DAVENPORT, Thomas H. Capital Humano: o que é e por que as pessoas investem nele. São Paulo, Nobel, 1999.

FREITAS, Luiz Carlos de. Os reformadores empresariais da educação: da desmoralização do magistério à destruição do sistema público de educação. Campinas, Educação e Sociedade, v. 33, n. 119, p. 325-672, abr./jun. 2012.

GEWIRTZ Sharon e BALL, Stephen J. Do modelo de gestão do bem-estar social ao novo gerencialismo: mudanças discursivas sobre gestão escolar no mercado educacional. In: BALL, Stephen J e MAINARDES Jeferson. Políticas educacionais questões e dilemas. São Paulo: Cortez, 2011.

GRANCHO, João Henrique de Carvalho Dias. A autonomia das escolas em Portugal. Quadro de desenvolvimento e influências internacionais. Foro de Educación, n. 10, p. 231-244, 2008 .

GRANT, Janet. Principles of curriculum design. In: SWANWICK, Tim (org). Understanding medical education, evidence, theory and practice. Oxford, UK, WileyBlackwell, p. 1-15, 2010.

KLIEBARD, Herbert. Burocracia e teoria de currículo. Currículo sem Fronteiras, v. 11, n. 2, p. 5-22, jul./dez, 2011.

KNIGHT, Jane. Internationalization remodeled: definition, approaches and rationales. Journal of Studies in International Education, v. 8, n. 1, p. 5-31, 2004.

KNIGHT, Jane. Higher Education in Turmoil: The changing world of internationalization. Sense Pub: The Netherlands, 2008. 
KNIGHT, Jane. International education Hubs: Student, talent, knowledge-innovation models. Springer Netherlands, 2014.

LANDWEHR, Megan M. Internationalization of K-12 Schools Through the Eyes of Public School Principals. Capstone Collection, SIT Graduate Institute, p. 5-25, spring, 2012. Disponível em: http://digitalcollections.sit.edu/capstones/index.5.html. Acesso em: 10 out. 2017.

LEASK, Betty. Using formal and informal curricula to improve interactions between home and international students. Journal of Studies in International Education: v. 13, n. 2, p. 205-221, 2009.

LEASK, Betty. Internationalizing the curriculum. New York: Routledge, 2015.

LIBÂNEO, José Carlos. Internacionalização das políticas educacionais: elementos para uma análise pedagógica de orientações curriculares para o ensino fundamental e de propostas para a escola pública. In: SILVA, Maria Abadia e CUNHA, Carlos (org). Educação Básica: políticas, avanços, pendências. Campinas: Autores Associados, p. 13-56, 2014.

\section{LONGVIEW FOUNDATION FOR EDUCATION IN WORLD AFFAIRS AND} INTERNATIONAL UNDERSTANDING, INC. Teacher Preparation for the Global Age: The imperative for change, 2008.

MAUÉS, Olgaises Cabral.; WONDJE, Calixte.; GAUTHIER, Clermont. Duas perspectivas diferentes em relação à abordagem por competências no ensino: os casos do Brasil e do Quebec. GT de Formação de Professores, n. 08. 2004. Disponível em: www.anped.org.br/25/olgaisesmauest08.rtf. Acesso em: 25 fev. 2016.

MEDEIROS, Sonayra e RODRIGUES, Melânia. O gerencialismo, reforma do Estado e da educação no Brasil. Revista Educação em Questão, Natal, v. 48, n. 34, p. 216-240, jan./abr. 2014.

MOREIRA, Antonio Flávio. O currículo como política cultural e a formação docente. In: SILVA, Tomaz Tadeu e MOREIRA, Antonio Flávio (org). Territórios contestados, o currículo e os novos mapas políticos e culturais. Petrópolis: Vozes, 1999.

PIERANTI, Octávio; RODRIGUES, Silvia e PECI, Alketa. Governança e New Public Management: convergências e contradições no contexto brasileiro. O\&S, v. 15, n. 46, jul./set. 2008.

POPKEWITZ Thomas. O duplo significado de cosmopolitismo e os estudos comparados de educação. In: COWEN, Robert; KAZAMIAS, Andreas e ULTERHALTER, Elaine (org). Educação comparada: panorama internacional e perspectivas. Brasília: UNESCO, CAPES, 2012.

SEVILHA, Gustavo Brechese. A internacionalização do ensino básico, suas motivações. 2014. Dissertação (Ciência Política) Universidade de São Paulo: Departamento de Ciência Política, 2014. 
SHAKLEE, Beverly e BAILY, Supriya (org). Internationalizing teacher education in the United States. Lanham, MD: Rowman \& Littlefield Education Publishing Group, 2012. SILVA, Tomaz Tadeu da; MOREIRA, Antonio Flavio (org). Territórios Contestados: o currículo e os novos mapas políticos e culturais. Petrópolis, RJ: Vozes, 1995.

SILVA JR, João dos Reis; LUCENA, Carlos e FERREIRA, Luciana Rodrigues. As relações entre o ensino médio e a educação superior no Brasil: profissionalização e privatização. Campinas, Educação e Sociedade, v. 32, n. 116, p. 839-856, jul./set. 2011.

SOUZA, Marcel Garcia de. O Processo de Internacionalização Promovido pela Capes na Formação de Professores da Educação Básica. 2016. Dissertação (Mestrado em educação no Programa de Pós-Graduação em Educação em Ciências: Química da Vida e Saúde), URGS: 2016.

STEWART, Thomas. Capital intelectual: a nova vantagem competitiva das empresas. Rio de Janeiro: Campus, 1998.

UNESCO. Educação para a cidadania global: preparando alunos para os desafios do século XXI. Brasília: UNESCO, 2015.

\section{Como referenciar este artigo}

THIESEN, Juares da Silva. Currículos da Educação Básica Brasileira: convergências com o discurso educacional global em contextos de internacionalização. Revista Ibero-Americana de Estudos em Educação, Araraquara, v. 14, n. 2, p. 420-436, abr./jun., 2019. E-ISSN: 19825587. DOI: 10.21723/riaee.v14i2.11306

Submetido em: 19/04/2018

Aprovado em: 29/07/2018 